\title{
ORIGINAL ARTICLE Relatively high mortality risk in elderly Swedish subjects with low selenium status
}

\author{
U Alehagen ${ }^{1}$, P Johansson ${ }^{1}$, M Björnstedt ${ }^{2}$, A Rosén $^{3}$, C Post $^{3}$ and J Aaseth ${ }^{4}$
}

BACKGROUND/OBJECTIVES: The daily dietary intake of selenium (Se), an essential trace element, is still low in Sweden in spite of decades of nutritional information campaigns and the effect of this on the public health is presently not well known. The objective of this study was to determine the serum Se levels in an elderly Swedish population and to analyze whether a low Se status had any influence on mortality.

SUBJECTS/METHODS: Six-hundred sixty-eight $(n=668)$ elderly participants were invited from a municipality and evaluated in an observational study. Individuals were followed for 6.8 years and Se levels were re-evaluated in 98 individuals after 48 months. Clinical examination of all individuals included functional classification, echocardiography, electrocardiogram and serum Se measurement. All mortality was registered and endpoints of mortality were assessed by Kaplan-Meier plots, and Cox proportional hazard ratios adjusted for potential confounding factors were calculated.

RESULTS: The mean serum Se level of the study population $(n=668)$ was $67.1 \mu \mathrm{g} / \mathrm{l}$, corresponding to relatively low Se intake. After adjustment for male gender, smoking, ischemic heart disease, diabetes, chronic obstructive pulmonary disease and impaired heart function, persons with serum Se in the lowest quartile had 43\% (95\% confidence interval (Cl): 1.02-2.00) and 56\% (95\% Cl: 1.032.36) increased risk for all-cause and cardiovascular mortality, respectively. The result was not driven by inflammatory effects on Se concentration in serum.

CONCLUSION: The mean serum Se concentration in an elderly Swedish population was $67.1 \mu \mathrm{g} / \mathrm{l}$, which is below the physiological saturation level for several selenoprotein enzymes. This result may suggest the value of modest Se supplementation in order to improve the health of the Swedish population.

European Journal of Clinical Nutrition (2016) 70, 91-96; doi:10.1038/ejcn.2015.92; published online 24 June 2015

\section{INTRODUCTION}

The trace element selenium (Se) is essential for a number of cellular functions. The human selenoproteome has 25 separate genes encoding selenoproteins. ${ }^{1}$ These include glutathione peroxidase (GPX) family members, including cellular, extracellular, phospholipid hydroperoxide and gastrointestinal GPX. In addition, thioredoxin reductases (TXNRD) also protect tissues from oxidative stress. These proteins are important redox enzymes with a multitude of functions.

The essentiality of Se relates to its incorporation in the amino acid selenocysteine, which is present in the active sites of GPX and other selenoproteins. However, redox-active Se compounds may function both as pro-oxidants and antioxidants depending on species, concentration and the redox state of the cell. ${ }^{2,3}$ About half of the Se in whole blood is found in the plasma, of which selenoprotein P (SEPP1) usually constitutes more than $60 \%$ and GPX constitutes $25 \%{ }^{4}$ SEPP1 contains up to 10 selenocysteine residues and is the means of transporting Se around the body to tissues that need it. ${ }^{5}$ It has an antioxidative role in the blood ${ }^{6,7}$ and, among other biological effects, it is believed to be active in endothelial protection. ${ }^{5}$ In order to obtain the maximum level of SEPP1, an intake of about total $100 \mu \mathrm{g} /$ day was needed in an adult UK population, meaning that for that population a supplemental intake $50 \mu \mathrm{g} /$ day, in addition to the habitual intake of $\sim 55 \mu \mathrm{g} / \mathrm{day}$, was needed. ${ }^{8}$
The food intake of Se differs in various parts of the world. ${ }^{5}$ This is mainly explained by varying Se content in the soil, ${ }^{5}$ although different food habits may have a role.

The soils in North America have a significantly higher content of Se than in Europe; ${ }^{5}$ thus, the reported serum Se levels of US citizens are generally above $120 \mu \mathrm{g} / \mathrm{l}^{9,10}$ whereas levels below $90 \mu \mathrm{g} / \mathrm{l}$ have been reported from several European countries. ${ }^{11-15}$

The Nordic countries (Finland, Sweden, Norway and Denmark) represent low-Se areas in Europe. In Finland, the reported average intake of Se in the 1970s was $25 \mu \mathrm{g} /$ day and the reported average plasma Se level was $49.6 \mu \mathrm{g} / \mathrm{l} .{ }^{16}$ However, based on the low intake, the authorities in Finland decided to add Se to the fertilizers in 1986. ${ }^{17}$ The present average plasma Se level has therefore been raised to about $111 \mu \mathrm{g} / \mathrm{l}^{16}$ In Norway, the import of wheat grains from Northern America has resulted in levels around $90 \mu \mathrm{g} / \mathrm{l}$ in whole blood corresponding to a mean daily intake of about $50 \mu \mathrm{g} /$ day $^{18}$ which is higher than in Sweden and Denmark. ${ }^{19}$

Gao et al. ${ }^{20}$ reported an average serum Se level of $75.6 \mu \mathrm{g} / \mathrm{l}$ in a population of more than 1900 Swedish persons, indicating a daily intake well below the recommended lower limit. Harris et al. ${ }^{21}$ reported a very low Se intake of only $24.7 \mu \mathrm{g} /$ day in a Swedish population in which breast cancer was later diagnosed. Roman Vinas et al. $^{22}$ reported that between $31 \%$ and $47 \%$ of an adult and elderly population during 1997-1998 had an intake of Se below the estimated average requirement. These data indicate low Se

${ }^{1}$ Division of Cardiovascular Medicine, Department of Medical and Health Sciences, Heart Center, Linköping University, Linköping, Sweden; ${ }^{2}$ Division of Pathology F42, Department of Laboratory Medicine, Karolinska Institutet, Karolinska University Hospital Huddinge, Stockholm, Sweden; ${ }^{3}$ Division of Cell Biology, Department of Clinical and Experimental Medicine, Linköping University, Linköping, Sweden and ${ }^{4}$ Research Department, Innlandet Hospital Trust and Hedmark University College, Norway. Correspondence: Dr U Alehagen, Division of Cardiovascular Medicine, Department of Medical and Health Sciences, Heart Center, Linköping University, Linköping, SE-581 85, Sweden. E-mail: Urban.Alehagen@liu.se

Received 29 December 2014; revised 15 April 2015; accepted 19 April 2015; published online 24 June 2015 
levels in the Swedish population in general; however, few studies have investigated Se levels nor a possible association between low Se levels and negative health effects. Extended knowledge about this is important for decisions concerning public health.

The aim of the present study was to investigate whether there is still low Se status among elderly Swedes and, furthermore, to analyze whether low Se status is associated with altered mortality in the Swedish population investigated.

\section{MATERIALS AND METHODS}

\section{Participants}

The participants in this study were recruited from a rural municipality of 10300 inhabitants in the south-east of Sweden. All citizens in the municipality aged between 70 and 80 years were invited to participate in the study as part of a continuous epidemiological project in the municipality that had been running since 1998. From a population of 1130 individuals living in the municipality of the chosen age range, 876 individuals agreed to participate and of those 675 agreed to participate in a follow-up project that started in January 2003 and concluded in February 2010.

Of the 675 that consented to participate, 668 agreed that blood samples could be drawn and they were thus included in the present study for analysis of Se at the onset of the study. This population constituted the basal Se measurement population and the population from which mortality was analyzed.

Owing to the fact that 219 participants were randomized to participate in another study, they did not undergo the further risk evaluations of the present study. However, their measured baseline Se levels were used in this study. Thus, the final study population for the current risk evaluation consists of 449 individuals. Out of the 449 individuals, serum samples from 98 subjects were evaluated for Se after 48 months (Figure 1).

All the participants were examined by one of three experienced cardiologists. A new clinical history was recorded, a clinical examination was performed, Doppler echocardiography and a new electrocardiogram were carried out and the New York Heart Association functional class was assessed. The latter grades how a patient with heart disease experiences symptoms of tiredness, breathlessness or chest pain; it is graded from I to IV, where IV is symptoms already at rest. All-cause and cardiovascular mortalities were registered. The mortality information was obtained from the National Board of Health and Welfare in Sweden, which registers all deaths of Swedish citizens.

The study was approved by the Regional Ethical Committee (diary number 03-176) and conforms to the ethical guidelines of the 1975 Declaration of Helsinki. Written informed consent was obtained from all patients.

\section{Blood samples}

The blood samples were collected while the participants were resting and in a supine position. Pre-chilled EDTA vials were used. The vials were centrifuged at $3000 \mathrm{~g},+4{ }^{\circ} \mathrm{C}$, plasma was transferred to new vials and was frozen at $-70^{\circ} \mathrm{C}$. No samples were thawed until the analyses were carried out.

\section{Se analysis}

The serum Se analyses were performed using inductively coupled plasma mass spectrometry methodology at an Agilent 700 platform at Kompetenzzentrum für komplementärmedizinische Diagnostik, Zweigniederlassung der synlab MVZ Leinfelden GmbH (Leinfelden-Echterdingen, Germany). The accuracy of the measurements was checked by analyzing two external reference materials with certified values of 63 and $103 \mu \mathrm{g} / \mathrm{l}$ (control programme offered by the Society for Advancement of Quality Assurance in Medical Laboratories, INSTAND e.V., Düsseldorf, Germany), showing values within $90 \%-110 \%$ of certified concentrations. A roundrobin test with INSTAND e.V. always passed adequately. The precision of the method, checked by repetitive analyses of the same sera, showed an average coefficient of variation of $5.7 \%$.

\section{Echocardiography}

The Doppler echocardiographic examinations (Accuson XP-128C, Siemens Healthcare, Siemens AG, Erlangen, Germany) were performed with the participant in the left lateral position. The cardiac function expressed as ejection fraction readings were categorized into four classes, with interclass limits placed at 30\%, $40 \%$ and $50 \%{ }^{23,24}$ Normal systolic function

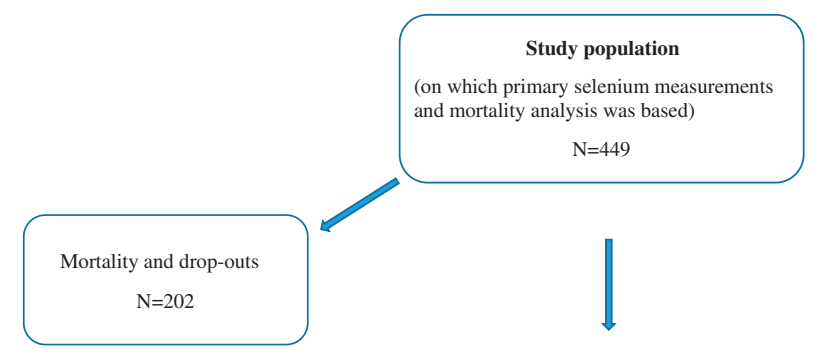

Follow-up study
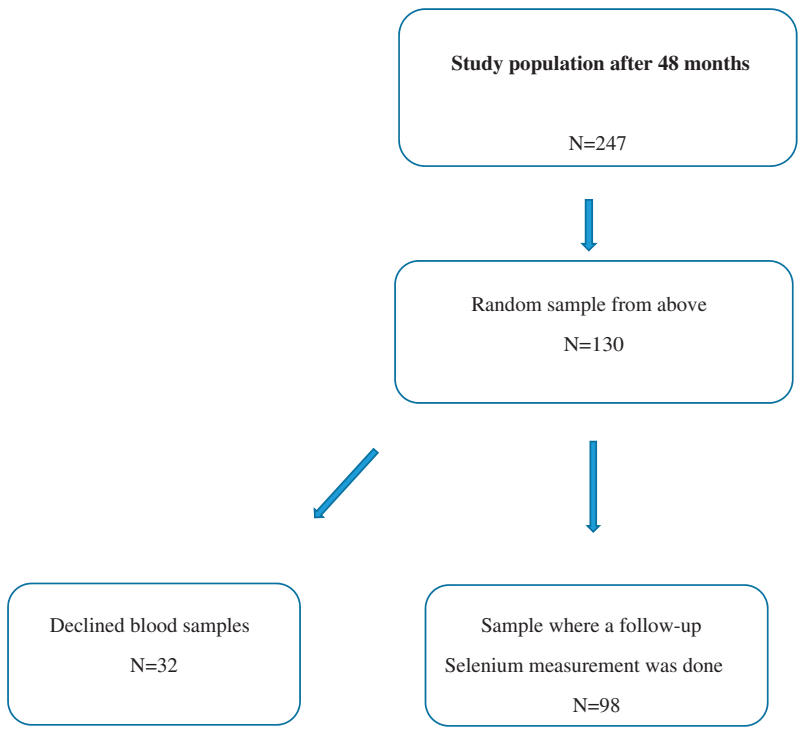

Figure 1. Flow chart of the study design.

was defined as ejection fraction $\geq 50 \%$, whereas severely impaired systolic function was defined as ejection fraction $<30 \%$.

\section{Statistics}

The descriptive data are presented as percentages or mean \pm s.d. The Student's unpaired two-sided $t$-test was used for continuous variables. For variables on the continuous scale level analysis of variance evaluations have been performed, and for variables on the nominal scale level multiple $x^{2}$-tests have been performed. Kaplan-Meier analyses were based on 449 participants illustrating the association between levels of Se and all-cause, and cardiovascular mortality during up to 2500 days. Basal level of Se was analyzed in 668 participants and the values were ordered into quartiles where the first quartile (that is, levels $<57.2 \mu \mathrm{g} / \mathrm{l}$ ) was evaluated against the second, third and fourth quartiles. Censored participants were those still living at the end of the study or those who had died for reasons other than all-cause/cardiovascular diseases. Completed participants were those who had died owing to all-cause/cardiovascular diseases.

Risk assessment in the serum Se quartiles was performed using univariate and multivariate Cox proportional hazard regressions. Factors that influence the measured Se levels include certain diseases and smoking. In the multivariate model, adjustments were made for the following clinical variables: male gender, smoking, ischemic heart disease, diabetes, chronic obstructive pulmonary disease and ejection fraction $<40 \%$ according to echocardiography.

$P$-values $<0.05$ were considered significant, based on two-sided evaluations. All data were analyzed using Statistica v12.0 software (Statsoft Inc., Tulsa, OK, USA).

\section{RESULTS}

Population baseline characteristics

The characteristics of the study population $(n=668)$ divided into the four quartiles of Se are presented in Table 1. Similar gender 
(female to male) ratios were found in the different quartiles, except in the fourth quartile. In the first quartile, the group was older and more participants in the third quartile were in the New York Heart Association functional class II. No significant difference was found between the four quartiles with respect to any other variable, including laboratory measures of inflammation.

\section{Serum Se concentrations}

At inclusion, the mean serum Se concentration was $67.1 \mu \mathrm{g} / \mathrm{l}$ (s.d. 16.8). The female participants had a concentration of $68.8 \mu \mathrm{g} / \mathrm{l}$ (s.d. 17.8) and the male participants had $65.2 \mu \mathrm{g} / \mathrm{l}$ (s.d. 15.5; $T=2.8$; $P=0.006$ ) (Table 2). Serum Se levels were determined again after 48 months in a subset of 98 randomized individuals. In these individuals, the values from the second measurement (for females: $70.8 \mu \mathrm{g} / \mathrm{l}$ in average and for males: $72.5 \mu \mathrm{g} / \mathrm{l}$ in average) showed higher concentrations at the second measurement after 48 months. A detailed analysis of the changes in serum Se concentration is shown in Table 3.
The current smokers had a lower serum Se concentration (mean $63.1 \mu \mathrm{g} / \mathrm{l}$; s.d. 17.3) compared with the non-smoking group (mean $67.7 \mu \mathrm{g} / \mathrm{l} ;$ s.d. 16.6).

Mortality rates in persons with low versus high Se

The participants were evaluated regarding possible association between Se level and mortality. Of the 449 participants in the total study population in which the risk evaluations were performed, 122 participants (27.2\%) died of all-cause mortality and 85 participants $(18.9 \%)$ died of cardiovascular mortality during the follow-up period of 2500 days (6.85 years).

A significant difference in mortality rates was found in persons with serum Se values grouped in the lowest Se (first) quartile versus those in the fourth quartiles. In the first quartile, 41 individuals out of 107 died versus 25 out of 111 in the fourth quartile, from all causes combined $\left(x^{2}: 6.44 ; P=0.01\right)$. Regarding cardiovascular mortality, the same trend was noted: $29 / 107$ in the first quartile and $16 / 111$ in the fourth quartile $\left(X^{2}: 5.35 ; P=0.02\right)$. An evaluation of the frequency of cancer mortality in the different

Table 1. Basal characteristics of the study population divided into quartiles of serum Se levels

\begin{tabular}{|c|c|c|c|c|c|}
\hline Variables & Quartile $1<57.2 \mu \mathrm{g} / \mathrm{l}$ & Quartile $257.2-67.1 \mu \mathrm{g} / \mathrm{l}$ & Quartile 3 67.1-76.1 $\mu \mathrm{g} / \mathrm{l}$ & Quartile $4>76.1 \mu \mathrm{g} / \mathrm{l}$ & P-value \\
\hline Males/females & $87 / 80$ & $78 / 89$ & $87 / 79$ & $67 / 101$ & \\
\hline \multicolumn{6}{|l|}{ History } \\
\hline Smoking, $n$ (\%) & $25(15.0)$ & $13(7.8)$ & $12(7.2)$ & $13(7.7)$ & 0.05 \\
\hline Diabetes, $n(\%)$ & 29 (17.4) & 39 (23.4) & $43(25.9)$ & 35 (20.8) & 0.27 \\
\hline NYHA class I, $n(\%)$ & $74(44.3)$ & $76(45.5)$ & $82(49.4)$ & $55(32.7)$ & $<0.001$ \\
\hline NYHA class II, $n(\%)$ & $47(28.1)$ & $56(33.5)$ & $46(27.7)$ & $55(32.7)$ & 0.54 \\
\hline NYHA class III, $n$ (\%) & $38(22.8)$ & $30(18.0)$ & $37(22.3)$ & $26(15.5)$ & 0.35 \\
\hline NYHA class IV, $n(\%)$ & $4(0.2)$ & 0 & 0 & 0 & \\
\hline \multicolumn{6}{|l|}{ Medication } \\
\hline ACE inhibitors, $n$ (\%) & $34(20.4)$ & $36(21.6)$ & $31(18.7)$ & $37(22.0)$ & 0.90 \\
\hline BP diastolic, $\mathrm{mm} \mathrm{Hg}( \pm$ s.d. $)$ & $75(9.5)$ & 76 (11.6) & 74 (11.9) & $75(12.6)$ & 0.46 \\
\hline $\mathrm{ECG}, \mathrm{AF}, n(\%)$ & $18(10.8)$ & $21(12.6)$ & $16(9.6)$ & $14(8.3)$ & 0.63 \\
\hline \multicolumn{6}{|l|}{$L a b$} \\
\hline $\mathrm{Hb}<120 \mathrm{~g} / \mathrm{l}, n(\%)$ & $28(16.8)$ & $19(11.4)$ & $16(9.6)$ & $19(11.3)$ & 0.16 \\
\hline $\mathrm{EF}<40 \%, n(\%)$ & $16(9.6)$ & $16(9.6)$ & $18(10.8)$ & $13(7.7)$ & 0.43 \\
\hline hs-CRP mg/l (s.d.) & $4.2(6.5)$ & $3.0(3.2)$ & $3.3(3.7)$ & $5.5(22.0)$ & 0.71 \\
\hline sP-selectin $\mathrm{ng} / \mathrm{ml}$ (s.d.) & $55.1(23.4)$ & $57.7(25.4)$ & $59.0(22.3)$ & $59.3(27.4)$ & 0.81 \\
\hline
\end{tabular}

Abbreviations: $A F$, atrial fibrillation; $B P$, blood pressure; $C O P D$, chronic obstructive pulmonary disease; $E C G$, electrocardiogram; $E F$, ejection fraction from echocardiographic examination; hs-CRP, high-sensitivity analysis of C-reactive protein; NYHA, New York Heart Association functional class; Se, selenium. $P$-values $<0.05$ were considered significant, all $P$-values obtained from analysis of variance evaluation.

Table 2. Serum Se measurement in the study population in two instances

\begin{tabular}{lcrrr}
\hline & Total population & Females & Males & P-value \\
\hline Measurement no. 1, $\mu \mathrm{g} / \mathrm{l}$, mean $( \pm \mathrm{s} . \mathrm{d})$. & $67.1(16.8)$ & $68.8(17.8)$ & $65.2(15.4)$ & $T=2.8 ; P=0.006$ \\
Measurement no. 2 after 48 months, $\mu \mathrm{g} / \mathrm{l}$, mean $( \pm$ s.d.) & $71.6(24.9)$ & $70.80(25.9)$ & $72.5(23.9)$ & $T=0.32 ; P=0.75$ \\
\hline Abbreviations: Se, selenium; $T$, $T$-statistics. Measurement no. 1 consisted of 668 individuals. Measurement no. 2 consisted of 98 control individuals from the \\
above population.
\end{tabular}


Table 3. Change in serum selenium concentration between two measurements during 48 months follow-up

\begin{tabular}{lccc}
\hline & Change in selenium concentration & Change in selenium concentration $>30 \%$ & Change in selenium concentration $>50 \%$ \\
\hline Increasing concentration & $62 / 98(63.3 \%)$ & $26 / 98(26.5 \%)$ & $18 / 98(18.4 \%)$ \\
Decreasing concentration & $34 / 98(34.7 \%)$ & $7 / 98(7.1 \%)$ & $1 / 98(1.0 \%)$ \\
Unchanged concentration & $2 / 98(2.0 \%)$ & $2 / 98(2.0 \%)$ & $2 / 98(2.0 \%)$
\end{tabular}

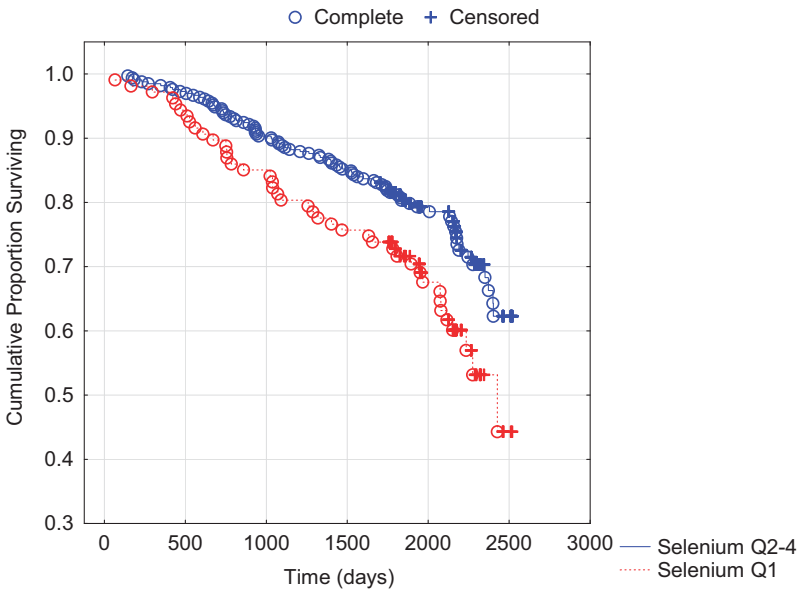

Persons at risk

\begin{tabular}{|l|c|c|c|c|c|c|}
\hline Quartiles & 0 days & 500 days & 1000 days & 1500 days & 2000 days & 2500 days \\
\hline Q1 & 111 & 105 & 95 & 85 & 49 & 5 \\
\hline Q2-4 & 338 & 329 & 306 & 289 & 115 & 28 \\
\hline
\end{tabular}

Figure 2. Cumulative proportion surviving from all-cause mortality analyzing serum concentration of $\mathrm{Se}$ in the first quartile versus second-to-fourth quartiles. Notes: Censored participants were those still living at the end of the study. Completed participants were those who had died. Persons at risk indicate the number of persons at a specific time point that are exposed to the risk of mortality.

quartiles of serum Se has also been performed. No difference in cancer mortality was found (data not shown).

A Kaplan-Meier analysis illustrating all-cause (Figure 2) and cardiovascular mortality (Figure 3 ) of the first quartile versus the second-to-fourth quartiles during the follow-up period in the population is shown.

Comparing the first quartile with the second-to-fourth quartiles, a $67 \%$ increased risk of all-cause mortality (hazard ratio: $1.67 ; 95 \%$ confidence interval $(\mathrm{Cl}): 1.15-2.44 ; P=0.007)$ in the univariate Cox proportional hazard regressions analyses was found, and regarding cardiovascular mortality a $73 \%$ increased risk (hazard ratio: 1.73; 95\% Cl: $1.10-2.72 ; P=0.02$ ) was found. Applying a multivariate model where well-known variables influencing risk of mortality as well as serum Se were included, an independent and significantly increased risk of $43 \%$ for all-cause mortality and $56 \%$ for cardiovascular mortality was found (Table 4).

\section{DISCUSSION}

In the present study, serum Se concentrations from a population of elderly healthy Swedes were low $(\sim 67.1 \mu \mathrm{g} / \mathrm{l})$ compared with the reported Se levels in the United States ${ }^{25,26}$ and also relatively low in comparison with values in other regions in Europe. ${ }^{18,19,27-32}$ The difference in concentrations between smokers and nonsmokers in the present study was not significant, which may be an effect of the small size of the smoking group ( $n=40 ; 9.0 \%)$, as some studies have found decreased levels in current smokers. ${ }^{33,19}$ However, there are also studies where such an association has not been found. ${ }^{34}$

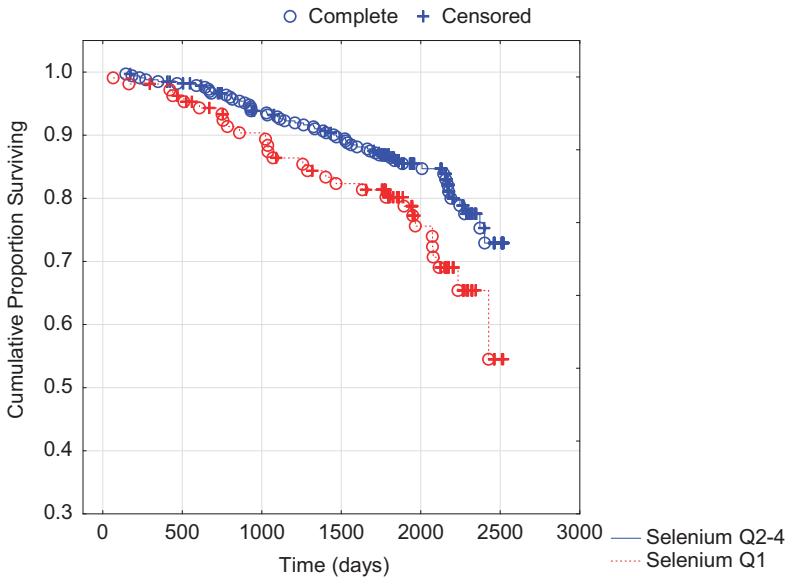

Persons at risk

\begin{tabular}{|l|c|c|c|c|c|c|}
\hline Quartiles & 0 days & 500 days & 1000 days & 1500 days & 2000 days & 2500 days \\
\hline Q1 & 111 & 105 & 95 & 85 & 49 & 5 \\
\hline Q2-4 & 338 & 329 & 306 & 289 & 115 & 28 \\
\hline
\end{tabular}

Figure 3. Cumulative proportion surviving from cardiovascular mortality analyzing serum concentration of Se in the first quartile versus second-to-fourth quartiles. Note: Censored participants were those still living at the end of the study or those who had died due to reasons other than cardiovascular diseases. Completed participants were those who had died due to cardiovascular diseases.

The present Nordic recommendations are $50 \mu \mathrm{g} /$ day for females and $60 \mu \mathrm{g} /$ day for males. ${ }^{35}$ The serum Se concentrations measured in our study are lower than the values achieved by these recommendations. Thus, a recent Norwegian study indicated that an average dietary intake of $50 \mu \mathrm{g} \mathrm{Se} /$ day resulted in serum levels around $90 \mu \mathrm{g} / \mathrm{l}^{18}$

The most interesting finding in our study was a significantly increased mortality among those in the lowest Se quartile $(<57.2 \mu \mathrm{g} / \mathrm{l})$. This segment of the population had $43 \%$ increased risk for all-cause mortality and $56 \%$ increased risk for cardiovascular mortality. As a low Se level could be a result of disease, we therefore evaluated the low Se level and adjusted for well-known clinical conditions that could influence mortality risk. Low Se level was still a significant and independent risk factor for both all-cause and cardiovascular mortality, and the difference in mortality could not obviously be explained by different inflammatory response, as two biomarkers for inflammation did not differ across the four Se quartiles.

Suadacini et al. ${ }^{36}$ from Denmark showed in a prospective cohort of more than 3000 males that serum Se concentrations below $60 \mu \mathrm{g} / \mathrm{l}$ were associated with increased risk of myocardial infarction. Finnish studies from the 1970s have also observed this association between low serum $\mathrm{Se}$ and increased risk of cardiovascular mortality. ${ }^{37}$ A study of an elderly French population, referred to as the EVA study, also reported an association between low plasma concentration of $\mathrm{Se}$ and increased mortality. ${ }^{38}$ In a small study from Spain, Millán Adame et al. ${ }^{39}$ reported that half of the evaluated population was Se deficient, as their plasma concentration was insufficient for maximal GPX activity, which requires $90 \mu \mathrm{g} / \mathrm{l}$. Letsiou et al. ${ }^{13}$ reported in a study 
Table 4. Multivariate Cox proportional hazard regression analysis of the relation between low serum Se and various clinical variables in relation to all-cause and cardiovascular mortality in the study population during a follow-up period of 48 months

\begin{tabular}{|c|c|c|c|c|c|c|}
\hline \multirow[t]{2}{*}{ Variables } & \multicolumn{3}{|c|}{ All-cause mortality } & \multicolumn{3}{|c|}{ Cardiovascular mortality } \\
\hline & Hazard ratio & $95 \% \mathrm{Cl}$ & P-value & Hazard ratio & $95 \% \mathrm{Cl}$ & P-value \\
\hline Male & 1.38 & $0.99-1.91$ & 0.06 & 1.25 & $0.83-1.88$ & 0.30 \\
\hline Smoker & 1.96 & $1.31-2.94$ & 0.001 & 1.83 & $1.09-3.08$ & 0.02 \\
\hline IHD & 1.41 & $0.81-1.61$ & 0.45 & 1.30 & $0.85-1.99$ & 0.22 \\
\hline
\end{tabular}

on more than 500 individuals from Greece that $>87 \%$ of the participants had a lower Se concentration than needed for optimal function of GPX. The same message was reported from the Czech Republic, where a majority of the 3000 blood donors investigated had lower Se concentration than needed for optimal activity of GPX. ${ }^{40}$ Finally, in 100 individuals living in Central Poland, a mean serum Se concentration of $51.1 \mu \mathrm{g} / \mathrm{l}$ was reported, which the authors showed was lower than required for cytoprotective gene expression. $^{41}$

These observations are also consistent with a meta-analysis of Se and coronary heart disease, which included 25 observational (14 cohort and 11 case-control studies) and six randomized controlled trials. ${ }^{42}$ In the meta-analysis, the pooled relative risks between the highest and lowest blood or toenail Se categories were $0.85(95 \% \mathrm{Cl}$ 0.74-0.99). A higher mean baseline Se intake was found in the six randomized controlled trials mentioned above, compared with our study. However, a more recent meta-analysis of 12 different trials by Rees et al. $^{43}$ (including the American Selenium and Vitamin E Cancer Prevention Trial (SELECT) and Nutritional Prevention of Cancer (NPC) Trial) could not support the finding that supplementation with Se decreased cardiovascular mortality. It should, however, be noted as mentioned by Hatfield and Gladyshev ${ }^{44}$ that both the SELECT and NPC studies included participants with mean plasma Se levels higher than in all European countries (135 and $113 \mu \mathrm{g} / \mathrm{l}$ respectively), and that those two studies comprised the vast majority of participants of the meta-analysis performed by Rees et al. ${ }^{43}$

Analysis of the participant group with two Se measurements in our study (at inclusion and at 48 months) revealed a statistically significant, but not high, correlation coefficient $(r=0.34)$ between the first and the second measurement. This low correlation could be a result of the discussion in the community where the study was performed, resulting in a novel interest in using Se supplementation. Thus, we observed that $63.3 \%$ (62 out of 98) had a higher serum Se concentration at the second measurement. The consequence is that results of those assigned to the first quartile may even be underestimated.

From the basal characteristics of the study population (Table 1), no difference could be found in the concentration of two biomarkers high-sensitivity C-reactive protein and soluble P-selectin between the four quartiles of Se, showing that it is unlikely that the mortality difference result from different levels of inflammation. One possible mechanism for the association between low Se and mortality could be found in the fact that selenoproteins (the GPX family of proteins, TXNRD and SEPP1) have a central role in the defense against oxidative stress, and that increased oxidative stress is reported in patients with ischemic heart disease. $^{45,46}$ In heart failure, the balance between cytosolic and mitochondrial reactive oxygen species have been reported to become distorted, leading to oxidative imbalance, mitochondrial dysfunction and eventually to cell death. ${ }^{47}$ As an insufficient level of Se will result in only partially functioning anti-oxidative defense, this could explain the increased mortality in the present study among those with low serum Se.

\section{CONCLUSION}

In the present study, serum Se levels in 668 elderly healthy Swedish persons were analyzed. The mean concentration, $67.1 \mu \mathrm{g} / \mathrm{l}$, is insufficient to achieve optimum function of important selenoproteins.

Significantly increased all-cause mortality and cardiovascular mortality were observed in persons with low serum Se concentrations in an almost 7-year follow-up. The data suggest health benefits from higher Se status. As indicated in our previous report from the same Swedish region, ${ }^{48}$ we suggest that Se supplementation should be recommended to persons with serum Se concentration below $57 \mu \mathrm{g} / \mathrm{l}$.

\section{CONFLICT OF INTEREST}

The authors declare no conflict of interest.

\section{ACKNOWLEDGEMENTS}

The study was supported by grants from the County Council of Östergötland and the University of Linköping to UA (PJ). Grants from Cancer-och Allergifonden financed the analyses of Se.

\section{AUTHOR CONTRIBUTIONS}

UA had full access to all of the data in the study and takes responsibility for the integrity of the data and the accuracy of the data analysis. Study concept and design: UA, JA, PJ, MB, AR and CP. Acquisition of data: UAand PJ. Analysis and interpretation of data: UA and PJ. Drafting of the manuscript: UA, PJ, MB and JA. Critical revision of the manuscript: $U A, J A, P J, M B, A R$ and CP. Statistical analysis: UA. Obtained funding: UA, MB and AR. Study supervision: UA, JA, MB and PJ.

\section{REFERENCES}

1 Kryukov GV, Castellano S, Novoselov SV, Lobanov AV, Zehtab O, Guigo R et al. Characterization of mammalian selenoproteomes. Science 2003; 300: 1439-1443.

2 Wallenberg M, Misra S, Bjornstedt M. Selenium cytotoxicity in cancer. Basic Clin Pharmacol Toxicol 2014; 114: 377-386.

3 Weekley $\mathrm{CM}$, Harris $\mathrm{HH}$. Which form is that? The importance of selenium speciation and metabolism in the prevention and treatment of disease. Chem Soc Rev 2013; 42: 8870-8894.

4 Dumont E, Vanhaecke F, Cornelis R. Selenium speciation from food source to metabolites: a critical review. Anal Bioanal Chem 2006; 385: 1304-1323.

5 Rayman MP. Selenium and human health. Lancet 2012; 379: 1256-1268.

6 Traulsen H, Steinbrenner H, Buchczyk DP, Klotz LO, Sies H. Selenoprotein P protects low-density lipoprotein against oxidation. Free Radic Res 2004; 38: 123-128. 
7 Burk RF, Hill KE. Selenoprotein P: an extracellular protein with unique physical characteristics and a role in selenium homeostasis. Annu Rev Nutr 2005; 25: 215-235.

8 Hurst R, Armah CN, Dainty JR, Hart DJ, Teucher B, Goldson AJ et al. Establishing optimal selenium status: results of a randomized, double-blind, placebocontrolled trial. Am J Clin Nutr 2010; 91: 923-931.

9 Kafai MR, Ganji V. Sex age, geographical location, smoking, and alcohol consumption influence serum selenium concentrations in the USA: third National Health and Nutrition Examination Survey, 1988-1994. J Trace Elem Med Biol 2003; 17: $13-18$.

10 Bleys J, Navas-Acien A, Laclaustra M, Pastor-Barriuso R, Menke A, Ordovas J et al. Serum selenium and peripheral arterial disease: results from the national health and nutrition examination survey, 2003-2004. Am J Epidemiol 2009; 169: 996-1003

11 Van Cauwenbergh R, Robberecht H, Van Vlaslaer V, Deelstra H. Comparison of the serum selenium content of healthy adults living in the Antwerp region (Belgium) with recent literature data. J Trace Elem Med Biol 2004; 18: 99-112.

12 Burri J, Haldimann M, Dudler V. Selenium status of the Swiss population: assessment and change over a decade. J Trace Elem Med Biol 2008; 22: $112-119$.

13 Letsiou S, Nomikos T, Panagiotakos D, Pergantis SA, Fragopoulou E, Antonopoulou $S$ et al. Serum total selenium status in Greek adults and its relation to age. The ATTICA study cohort. Biol Trace Elem Res 2009; 128: 8-17.

14 Spina A, Guallar E, Rayman MP, Tigbe W, Kandala NB, Stranges S. Anthropometric indices and selenium status in British adults: the U.K. National Diet and Nutrition Survey. Free Radic Biol Med 2013; 65: 1315-1321.

15 Galan-Chilet I, Tellez-Plaza M, Guallar E, De Marco G, Lopez-Izquierdo R, GonzalezManzano I et al. Plasma selenium levels and oxidative stress biomarkers: a geneenvironment interaction population-based study. Free Radic Biol Med 2014; 74C: 229-236.

16 Alfthan G, Eurola M, Ekholm P, Venalainen ER, Root T, Korkalainen K et al. Effects of nationwide addition of selenium to fertilizers on foods, and animal and human health in Finland: from deficiency to optimal selenium status of the population. J Trace Elem Med Biol 2014; 31: 142-147.

17 Koivistoinen P, Huttunen JK. Selenium in food and nutrition in Finland. An overview on research and action. Ann Clin Res 1986; 18: 13-17.

18 Birgisdottir BE, Knutsen HK, Haugen M, Gjelstad IM, Jenssen MT, Ellingsen DG et al. Essential and toxic element concentrations in blood and urine and their associations with diet: results from a Norwegian population study including highconsumers of seafood and game. Sci Total Environ 2013; 463-464: 836-844.

19 Ellingsen DG, Thomassen Y, Rustad P, Molander P, Aaseth J. The time-trend and the relation between smoking and circulating selenium concentrations in Norway. J Trace Elem Med Biol 2009; 23: 107-115.

20 Gao H, Hagg S, Sjogren P, Lambert PC, Ingelsson E, van Dam RM. Serum selenium in relation to measures of glucose metabolism and incidence of Type 2 diabetes in an older Swedish population. Diabet Med 2014; 31: 787-793.

21 Harris HR, Bergkvist L, Wolk A. Selenium intake and breast cancer mortality in a cohort of Swedish women. Breast Cancer Res Treat 2012; 134: 1269-1277.

22 Roman Vinas B, Ribas Barba L, Ngo J, Gurinovic M, Novakovic R, Cavelaars A et al. Projected prevalence of inadequate nutrient intakes in Europe. Ann Nutr Metab 2011; 59: 84-95.

23 Jensen-Urstad K, Bouvier F, Hojer J, Ruiz H, Hulting J, Samad B et al. Comparison of different echocardiographic methods with radionuclide imaging for measuring left ventricular ejection fraction during acute myocardial infarction treated by thrombolytic therapy. Am J Cardiol 1998; 81: 538-544.

24 van Royen N, Jaffe CC, Krumholz HM, Johnson KM, Lynch PJ, Natale D et al. Comparison and reproducibility of visual echocardiographic and quantitative radionuclide left ventricular ejection fractions. Am J Cardiol 1996; 77: 843-850.

25 Bleys J, Navas-Acien A, Guallar E. Serum selenium levels and all-cause, cancer, and cardiovascular mortality among US adults. Arch Intern Med 2008; 168: 404-410.

26 Lippman SM, Klein EA, Goodman PJ, Lucia MS, Thompson IM, Ford LG et al. Effect of selenium and vitamin $E$ on risk of prostate cancer and other cancers: the Selenium and Vitamin E Cancer Prevention Trial (SELECT). JAMA 2009; 301: 39-51.

27 Pestitschek M, Sonneck-Koenne C, Zakavi SR, Li S, Knoll P, Mirzaei S. Selenium intake and selenium blood levels: a novel food frequency questionnaire. Wien Klin Wochenschr 2013; 125: 160-164.

28 Suadicani $\mathrm{P}$, Hein $\mathrm{HO}$, Gyntelberg F. Serum selenium level and risk of lung cancer mortality: a 16-year follow-up of the Copenhagen Male Study. Eur Respir J 2012; 39: $1443-1448$.
29 Letsiou S, Nomikos T, Panagiotakos D, Pergantis SA, Fragopoulou E, Antonopoulou $S$ et al. Dietary habits of Greek adults and serum total selenium concentration: the ATTICA study. Eur J Nutr 2010; 49: 465-472.

30 Doupis J, Stavrianos C, Saltiki K, Mantzou E, Mastrokostopoulos A, Philippou G et al. Thyroid volume, selenium levels and nutritional habits in a rural region in Albania. Hormones (Athens) 2009; 8: 296-302.

31 Stranges S, Laclaustra M, Ji C, Cappuccio FP, Navas-Acien A, Ordovas JM et al. Higher selenium status is associated with adverse blood lipid profile in British adults. J Nutr 2010; 140: 81-87.

32 Hercberg S, Galan P, Preziosi P, Bertrais S, Mennen L, Malvy D et al. The SU.VI MAX Study: a randomized, placebo-controlled trial of the health effects of antioxidant vitamins and minerals. Arch Intern Med 2004; 164: 2335-2342.

33 Karunasinghe N, Han DY, Zhu S, Yu J, Lange K, Duan H et al. Serum selenium and single-nucleotide polymorphisms in genes for selenoproteins: relationship to markers of oxidative stress in men from Auckland, New Zealand. Genes Nutr 2012; 7: 179-190.

34 Hughes DJ, Fedirko V, Jenab M, Schomburg L, Meplan C, Freisling $\mathrm{H}$ et al. Selenium status is associated with colorectal cancer risk in the European prospective investigation of cancer and nutrition cohort. Int J Cancer 2015; 136: 1149-1161.

35 Nordic nutrition recommendations 2012: integrating nutrition and physical activity. 2014. Publication no. Nord 2014-002.

36 Suadicani $P$, Hein HO, Gyntelberg F. Serum selenium concentration and risk of ischaemic heart disease in a prospective cohort study of 3000 males. Atherosclerosis 1992; 96: 33-42.

37 Salonen JT, Alfthan G, Huttunen JK, Pikkarainen J, Puska P. Association between cardiovascular death and myocardial infarction and serum selenium in a matched-pair longitudinal study. Lancet 1982; 2: 175-179.

38 Akbaraly NT, Arnaud J, Hininger-Favier I, Gourlet V, Roussel AM, Berr C. Selenium and mortality in the elderly: results from the EVA study. Clin Chem 2005; 51: 2117-2123.

39 Millan Adame E, Florea D, Saez Perez L, Molina Lopez J, Lopez-Gonzalez B, Perez de la Cruz A et al. Deficient selenium status of a healthy adult Spanish population. Nutr Hosp 2012; 27: 524-528.

40 Benes B, Spevackova V, Smid J, Batariova A, Cejchanova M, Zitkova L. Effects of age, BMI, smoking and contraception on levels of $\mathrm{Cu}$, Se and $\mathrm{Zn}$ in the blood of the population in the Czech Republic. Cent Eur J Public Health 2005; 13: 202-207.

41 Reszka E, Wieczorek E, Jablonska E, Janasik B, Fendler W, Wasowicz W. Association between plasma selenium level and NRF2 target genes expression in humans. J Trace Elem Med Biol 2014; 30: 102-106.

42 Flores-Mateo G, Navas-Acien A, Pastor-Barriuso R, Guallar E. Selenium and coronary heart disease: a meta-analysis. Am J Clin Nutr 2006; 84: 762-773.

43 Rees K, Hartley L, Day C, Flowers N, Clarke A, Stranges S. Selenium supplementation for the primary prevention of cardiovascular disease. Cochrane Database Syst Rev 20131 CD009671.

44 Hatfield DL, Gladyshev VN. The outcome of Selenium and Vitamin E Cancer Prevention Trial (SELECT) reveals the need for better understanding of selenium biology. Mol Interv 2009; 9: 18-21.

45 Heitzer T, Schlinzig T, Krohn K, Meinertz T, Munzel T. Endothelial dysfunction, oxidative stress, and risk of cardiovascular events in patients with coronary artery disease. Circulation 2001; 104: 2673-2678.

46 Vassalle C, Bianchi S, Bianchi F, Landi P, Battaglia D, Carpeggiani C. Oxidative stress as a predictor of cardiovascular events in coronary artery disease patients. Clin Chem Lab Med 2012; 50: 1463-1468.

47 Verdejo HE, del Campo A, Troncoso R, Gutierrez T, Toro B, Quiroga C et al. Mitochondria, myocardial remodeling, and cardiovascular disease. Curr Hypertens Rep 2012; 14: 532-539.

48 Alehagen $U$, Johansson $\mathrm{P}$, Bjornstedt $\mathrm{M}$, Rosen A, Dahlstrom U. Cardiovascular mortality and N-terminal-proBNP reduced after combined selenium and coenzyme Q10 supplementation: a 5-year prospective randomized double-blind placebo-controlled trial among elderly Swedish citizens. Int J Cardiol 2013; 167: 1860-1866.

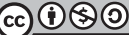

This work is licensed under a Creative Commons AttributionNonCommercial-ShareAlike 4.0 International License. The images or other third party material in this article are included in the article's Creative Commons license, unless indicated otherwise in the credit line; if the material is not included under the Creative Commons license, users will need to obtain permission from the license holder to reproduce the material. To view a copy of this license, visit http:// creativecommons.org/licenses/by-nc-sa/4.0/ 